\title{
Increased Plasma Beta-Hydroxybutyrate, Preserved Cerebral Energy Metabolism, and Amelioration of Brain Damage During Neonatal Hypoxia Ischemia with Dexamethasone Pretreatment
}

\author{
BERNARD J. DARDZINSKI, SHERI L. SMITH, JAVAD TOWFIGHI, GERALD D. WILLIAMS, \\ ROBERT C. VANNUCCI, AND MICHAEL B. SMITH \\ Departments of Radiology, Center for NMR Research [S.L.S., G.D.W., M.B.S.], Cellular and Molecular \\ Physiology [M.B.S.], Pediatrics [R.C.V.], and Pathology [J.T.], The Pennsylvania State University College \\ of Medicine, Hershey, Pennsylvania 17033, U.S.A.; and Departments of Radiology and Pediatrics, \\ University of Cincinnati College of Medicine, Imaging Research Center, Children's Hospital Medical \\ Center, Cincinnati, Ohio 45229, U.S.A. [B.J.D.]
}

\section{ABSTRACT}

Dexamethasone (DEX) pretreatment has been shown to be neuroprotective in a neonatal rat model of hypoxia ischemia (HI). The exact mechanism of this neuroprotection is still unknown. This study used ${ }^{31} \mathrm{P}$ nuclear magnetic resonance spectroscopy to monitor energy metabolism during a 3-h episode of HI in 7-d-old rat pups in one of two groups. The first group was pretreated with $0.1 \mathrm{~mL}$ saline (i.p.) and the second group was treated with 0.1 $\mathrm{mL}$ of $0.1 \mathrm{mg} / \mathrm{kg}$ DEX (i.p.) $22 \mathrm{~h}$ before HI. Animals pretreated with DEX had elevated nucleoside triphosphate and phosphocreatine levels during HI when compared with controls. Salinetreated animals had significant decreases in nucleoside triphosphate and phosphocreatine and increases in inorganic phosphate over this same period. ${ }^{31} \mathrm{P}$ nuclear magnetic resonance data unequivocally demonstrate preservation of energy metabolism during $\mathrm{HI}$ in neonatal rats pretreated with DEX. Animals pretreated with DEX had little or no brain damage following $3 \mathrm{~h}$ of HI when compared with matched controls, which experienced severe neuronal loss and cortical infarction. These same pretreated animals had an increase in blood beta-hydroxybutyrate levels before ischemia, suggesting an increase in ketone bodies, which is the neonate's primary energy source. Elevation of ketone bodies appears to be one of the mechanisms by which DEX pretreatment provides neuroprotection during $\mathrm{HI}$ in the neonatal rat. (Pediatr Res 48: 248-255, 2000)
DEX, dexamethasone
HI, hypoxia ischemia
NTP, nucleoside triphosphate
NMR, nuclear magnetic resonance
NMRS, nuclear magnetic resonance spectroscopy
BHB, beta-hydroxybutyrate
D- $\beta$-HBA, D- $\beta$-hydroxybutyrate dehydrogenase

\section{Abbreviations}

Dexamethasone (DEX) is a synthetic glucocorticoid. A National Institutes of Health consensus committee has recommended its use for women who are believed to deliver prematurely (1). Administered antenatally (before birth), DEX can relieve or ameliorate symptoms associated with respiratory distress syndrome and intraventricular hemorrhage and thus reduce mortality. Research was recommended to guide clinical care on the "effects of antenatal corticosteroids on hypoxic-ischemic insults."

Received August 8, 1998; accepted November 11, 1999.

Correspondence: Michael B. Smith, Ph.D., Center for NMR Research, Radiology MC H066, Penn State College of Medicine, Hershey Medical Center, 500 University Drive, Hershey, PA 17033, U.S.A.

Funding for this research was provided by National Institutes of Health program project grant 1P01HD30704-01A1.
The first study to document the effects of DEX on neonatal animals was performed using the modified Levine preparation in neonatal rat by Altman et al. (2). They s.c. injected rat pups with either saline, $4 \mathrm{mg} / \mathrm{kg}$ DEX, or $40 \mathrm{mg} / \mathrm{kg}$ DEX immediately before hypoxia ischemia (HI). Neither dose of DEX ameliorated brain edema, lactacidemia, or hypoglycemia. In addition, there was no preservation of high-energy metabolites and there was an increase in mortality associated with the highest dose. These negative results made other investigators reluctant to pursue DEX as an effective neuroprotective agent.

Barks et al. discovered that pretreatment with DEX $3 \mathrm{~h}$ or more before a hypoxic-ischemic insult was neuroprotective (3). DEX at $0.5 \mathrm{mg} / \mathrm{kg} / \mathrm{d}$ for $3 \mathrm{~d}$, before the insult, prevented brain damage associated with $3 \mathrm{~h}$ of cerebral $\mathrm{HI}$ in the 7-d-old rat 
pup (PND 7) (modified Levine preparation). Pretreatment with a dose of $0.01 \mathrm{mg} / \mathrm{kg} / \mathrm{d}$ for $3 \mathrm{~d}$ before HI prevented cerebral infarction. They also found that a single dose of $0.1 \mathrm{mg} / \mathrm{kg}$ given $24 \mathrm{~h}$ before the insult prevented cerebral infarction. Similar to Altman et al. (2), when a single dose was administered $3 \mathrm{~h}$ or immediately before $\mathrm{HI}$, there was no protective effect. A decrease in somatic growth and posthypoxic hyperglycemia with DEX administration was documented (3).

Investigations by Tuor et al. examined whether hyperglycemia or endogenous free radical scavengers could explain the neuroprotective effect of DEX. Using the same PND 7 rat pup model of HI, they elevated glucose levels during HI to the post-HI level of DEX-treated animals. This was accomplished by repeated injection of $10 \%$ glucose. Glucose and DEX animals had less damage than controls but glucose-treated animals were more severely damaged than animals pretreated with DEX (4). They also found that endogenous activities of several different antioxidant enzymes are not altered by DEX treatment or by $3 \mathrm{~h}$ of $\mathrm{HI}$ in neonatal rats. Hyperglycemia alone could not account for the neuroprotective effect of DEX.

Experiments by this same group examined whether DEX pretreatment improves local cerebral blood flow (5). Cerebral blood flow was measured by autoradiography after either 2 or $3 \mathrm{~h}$ of HI in animals pretreated with either DEX or saline. Pathologic results were similar to previous experiments: salinetreated animals had mean areas of damage of about $60 \%$ to $70 \%$ and DEX-treated animals had mean areas of damage of less than $2 \%$. Cerebral blood flow was reduced $60 \%$ to $80 \%$ ipsilateral to the carotid artery occlusion in animals treated with either saline or DEX. DEX does not improve local cerebral perfusion. A recent review article by Tuor explores the effects of DEX and the prevention of neonatal hypoxicischemic brain damage (6).

A single low dose of the synthetic glucocorticoid DEX, 6 to $24 \mathrm{~h}$ before $\mathrm{HI}$, will prevent cerebral infarction in the neonatal rat $(3,6)$. Although the neuroprotective mechanism remains unknown, possible suggested explanations include growth retardation, blood brain barrier permeability alteration, hyperglycemia, or increased glucose utilization. Alternatively, we propose DEX might create additional nucleoside triphosphate (NTP) producing substrates, where about $70 \%$ of NTP is ATP. There have been no previous studies on determining whether DEX affects cerebral energy metabolism.

In this study, we measured the effect of DEX pretreatment on high-energy cerebral metabolism, with ${ }^{31} \mathrm{P}$ nuclear magnetic resonance spectroscopy (NMRS) during $\mathrm{HI}$ in the PND 7 rat to try to determine its role in neuroprotection. Blood levels of glucose and beta-hydroxybutyrate (BHB) were measured before and after $3 \mathrm{~h}$ of $\mathrm{HI}$ to determine whether DEX pretreatment alters these metabolic substrates. Increased levels of BHB might provide a critical and supplemental energy asset for the PND 7 rat undergoing HI.

\section{METHODS}

PND 7 Wistar (Charles River) rats, weighing 12-18 g, were anesthetized with halothane ( $4 \%$ for induction; $1-1.5 \%$ for maintenance) and $30 \%$ oxygen balance nitrous oxide. Under anesthesia (duration of $5 \mathrm{~min}$ or less), the right common carotid artery was ligated with 4.0 surgical silk. The surgical incision was sutured with 4.0 silk and the animals allowed to recover with their dams for $3 \mathrm{~h}$ before onset of HI.

Rat pups were subjected to $8 \%$ oxygen at $36^{\circ} \mathrm{C}$ for duration of $3 \mathrm{~h}$ either within the nuclear magnetic resonance (NMR) probe or in a specially constructed bench-top apparatus to accommodate an entire litter of rat pups at once.

Animals undergoing NMR procedures were allowed to recover in air for $2.5 \mathrm{~h}$ inside the spectrometer, whereas animals undergoing bench-top procedures were allowed to recover with their dams until sacrifice for neuropathology, water content measurements, or blood plasma assay for glucose or BHB.

All pups were injected i.p. with either $0.1 \mathrm{~mL}$ of physiologic saline or $0.1 \mathrm{~mL}$ of $0.1 \mathrm{mg}$ DEX per kg of rat mass at $22 \mathrm{~h}$ before the onset of HI. Table 1 is a summary of the experimental protocols described below.

${ }^{31} \boldsymbol{P}$ NMRS. HI was induced inside a heated NMRS probe chamber $(n=12)$. The rectal temperature was maintained at $36^{\circ} \mathrm{C}$ by a circulating warm water blanket. Serial ${ }^{31} \mathrm{P}$ NMRS was performed $30 \mathrm{~min}$ before, during $180 \mathrm{~min}$ of HI, and for 150 min post HI (recovery) with a Bruker AM400 spectrometer. An elliptical surface coil $(7 \times 10 \mathrm{~mm}$ in diameter $)$ was placed over the hemisphere ipsilateral to the ligation. The temporal resolution of the one-pulse recovery spectra was $10-20$ min depending on the number of averages (300 or 600, respectively) (7). All NMRS pups were killed $24 \mathrm{~h}$ post HI for sensitive neurologic scoring (8) by a neuropathologist to assess the extent of damage.

At the conclusion of the experiment, spectra were analyzed by integration of the peak areas for phosphomonesters, inorganic phosphate $\left(\mathrm{P}_{\mathrm{i}}\right)$, phosphodiesters, phosphocreatine $(\mathrm{PCr})$, and NTP. The areas were corrected for saturation effects using separately determined saturation factors to provide accurate quantitation when ratios were used (7). This is necessary to correct for distortions of peak areas due to rapid signal accumulation (interpulse delay $=2 \mathrm{~s}$ ).

Table 1. Summary of experimental protocols

\begin{tabular}{|c|c|c|c|}
\hline \multirow[b]{2}{*}{ Experiment } & \multirow[b]{2}{*}{ Goal } & \multicolumn{2}{|c|}{ Number of animals } \\
\hline & & $\begin{array}{l}\text { Saline } \\
\text { control }\end{array}$ & $\begin{array}{c}\text { Dexamethasone } \\
\text { pretreated }\end{array}$ \\
\hline${ }^{31} \mathrm{P}$ spectroscopy & $\begin{array}{l}\text { Determine status of } \\
\text { cerebral energy } \\
\text { metabolites before, } \\
\text { during, and after HI. }\end{array}$ & 6 & 6 \\
\hline $\begin{array}{l}\text { Brain swelling } \\
\text { (edema) }\end{array}$ & $\begin{array}{l}\text { Determine effectiveness of } \\
\text { dexamethasone by } \\
\text { measuring brain edema } \\
42 \mathrm{~h} \text { after HI. }\end{array}$ & 40 & 67 \\
\hline Neuropathology & $\begin{array}{l}\text { Determine region of brain } \\
\text { injury } 72 \mathrm{~h} \text { after HI. }\end{array}$ & 10 & 10 \\
\hline Blood level assays & $\begin{array}{l}\text { Measure plasma levels of } \\
\text { glucose and BHB } \\
\text { before and after } 3 \mathrm{~h} \text { of } \\
\text { HI. }\end{array}$ & 19 & 23 \\
\hline Blood level assays & $\begin{array}{l}\text { Determine if elevation of } \\
\text { plasma ketone body } \\
\text { levels prior to HI are } \\
\text { statistically significant. }\end{array}$ & 43 & 32 \\
\hline Totals & & 118 & 138 \\
\hline
\end{tabular}


Brain swelling. HI was induced inside a heated Delrin block $(n=107)$ at $36^{\circ} \mathrm{C}$. A total of 67 animals were treated with DEX before $\mathrm{HI}$ and 40 were injected with saline as controls. At $42 \mathrm{~h}$ post HI, PND 9 animals were killed to measure the brain water content (edema or swelling) as described previously to evaluate both water content and edema. These measurements provide an initial screening for treatment efficacy and to decide which treatment groups will ultimately be scored by histologic methods. The percentage of water content, $W C(\%)$, from the hemispheres contralateral and ipsilateral to the ligation were determined as follows:

$$
\mathrm{WC}(\%)=\left[\frac{(\text { WetWeight })-(\text { DryWeight })}{(\text { WetWeight })}\right] \cdot 100
$$

where WetWeight was the weight of harvested brain tissue and DryWeight was the weight of the same specimen after drying for a minimum of $48 \mathrm{~h}$ at $70^{\circ} \mathrm{C}$. Using this relationship, the contralateral hemisphere water content $\left(W C_{\text {Left }}\right)$, and the water content of the hemisphere ipsilateral to the carotid artery ligation $\left(W C_{\text {Right }}\right)$, and the percentage of edema, Edema $(\%)$, is calculated with the following expression:

$$
\operatorname{Edema}(\%)=\left[\frac{\left(W C_{\text {Right }}\right)-\left(W C_{\text {Left }}\right.}{\left(W C_{\text {Leff }}\right)}\right] \cdot 100
$$

Effective treatment was determined by statistical comparison of the Edema(\%) between treatment groups. Edema(\%) and water content are highly correlated with neurologic damage ( 7 , $9,10)$.

\section{Neuropathology}

In a separate set of animals $(n=20)$, histologic scoring was used to assess damage at $72 \mathrm{~h}$ of recovery. Ten animals were treated with DEX and 10 were treated with saline. After $3 \mathrm{~h}$ of $\mathrm{HI}$, the animals were allowed to recover with their dams until they were killed at $72 \mathrm{~h}$ post HI. The brains were fixated before neurologic scoring (8). When the brain was properly fixed, two 2-mm thick coronal tissue blocks were embedded in paraffin.

Microscopic evaluations of acute lesions were made from two hematoxylin- and eosin-stained coronal sections, one at the level of the anterior commissure (anterior level) and the other at the level of the infundibulum through the mid-portion of the median eminence (posterior level), which together include structures of the anterior cerebral cortex, striatum, posterior cerebral cortex, dorsal hippocampus, thalamus, and amygdaloid nucleus (Fig. 1).

For each animal a score of 0 to 5 (Table 2) was assigned to 1 of 22 different structures. Evaluation of each structure is as described by Cataltepe et al. (8). The total score for each animal was then added up to give the total neuropathologic score for that animal (range 0-110). This score was used to compare the DEX-treated group with the controls.

\section{Glucose and BHB Plasma Levels}

Blood levels of BHB and glucose were measured $(n=42)$ both prior and after $3 \mathrm{~h}$ of HI. Blood levels of BHB were measured before $\mathrm{HI}$ in another 75 animals.
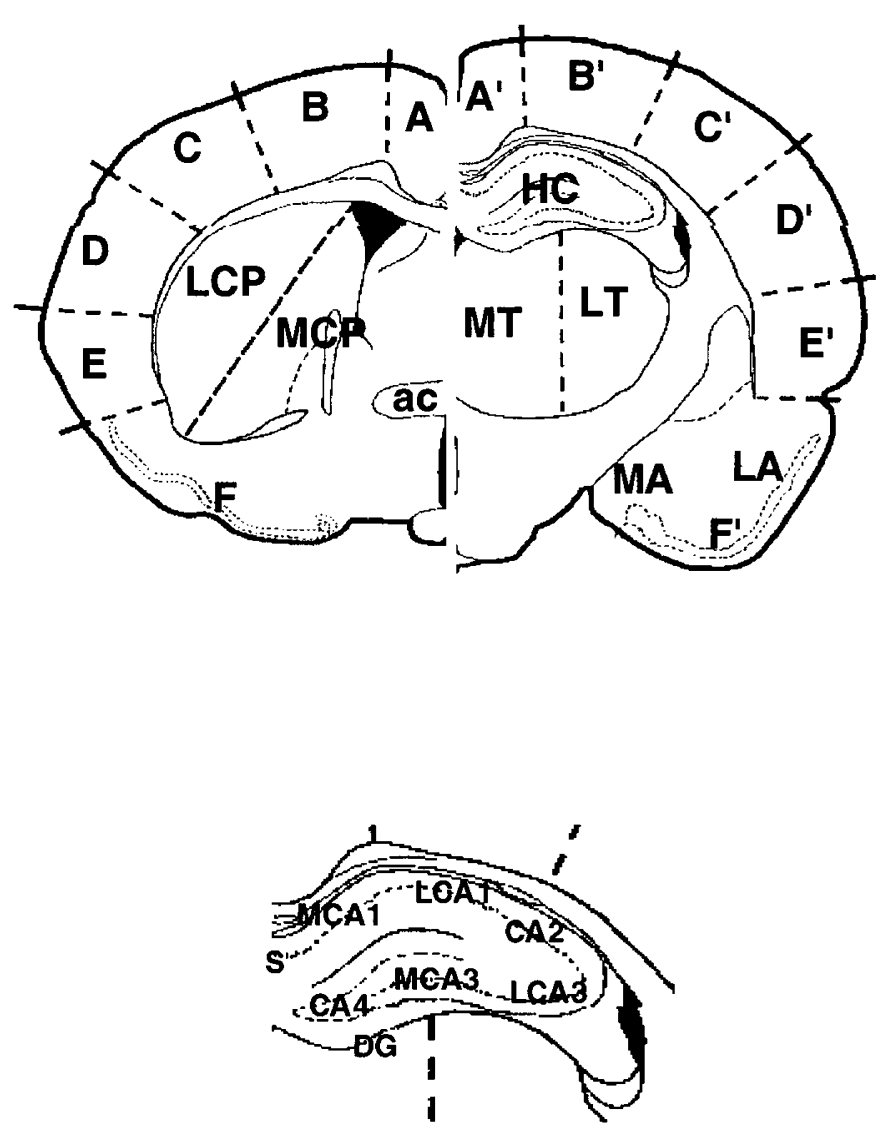

Figure 1. Diagrams of anterior (left) and posterior (right) level sections of the cerebral hemisphere of the immature rat. (Top) Structures are subdivided for histologic scoring of damage as given in Table 2. A-F and $\mathrm{A}^{\prime}-\mathrm{F}^{\prime}$ are cortical subdivisions; HC, hippocampus; LCP and MCP, lateral and medial caudoputamen; LT and MT, lateral and medial thalamus; ac, anterior commissure; LA and MA, lateral and medial amygdaloid nucleus. (Bottom) Expanded view of hippocampus (HC) for histological assessment. LCA1 and MCA1, lateral and medial CA1; LCA3 and MCA3, lateral and medial CA3; DG, dentate gyrus.

Table 2. Grading of degree of brain damage (Ref. 8)

\begin{tabular}{cl}
\hline Grade & \multicolumn{1}{c}{ Gray matter } \\
\hline 0 & Normal \\
1 & Few neurons damaged $(1 \%-5 \%)$ \\
2 & Several neurons damaged $(6 \%-25 \%)$ \\
3 & Moderate number of neurons damaged $(26 \%-50 \%)$ \\
4 & Greater than one-half of neurons damaged $(51 \%-75 \%)$ \\
5 & Majority or all neurons damaged including infarction $(>75 \%)$ \\
\hline
\end{tabular}

The concentration of metabolic substrates was determined in animal populations different from those used for NMRS, neuropathology, and water content determination. These separate experiments were necessary because of the small blood volume of neonatal rat pups. Blood was collected with heparinized capillary tubes by either tail snip or from decapitation. Measurements of metabolite concentrations were made via UVvisible spectrometry with a HP-8452A diode array spectrophotometer (Hewlett Packard, Palo Alto, CA, U.S.A.).

The method used used a diagnostic kit and reagents (Sigma Chemical Co. St. Louis, MO, U.S.A.) specific for glucose based on UV absorption of NADH. Increase in absorbance at $340 \mathrm{~nm}$ is proportional to the glucose concentration. Normal glucose concentrations for neonatal rats are between $7-8 \mathrm{mM}$. 
The principal BHB measurements rely on the oxidation of D- $\beta$-HBA to acetoacetate catalyzed by D-BHB-dehydrogenase. The increase in absorbance at $340 \mathrm{~nm}$ is proportional to the D-BHB content. The method used a commercial diagnostic kit and reagents (Sigma Chemical Co., St. Louis, MO, U.S.A.).

\section{RESULTS AND DISCUSSION}

${ }^{31} \boldsymbol{P}$ NMRS. NMRS pups pretreated with saline were extensively damaged, whereas those pups treated with DEX were not. ${ }^{31} \mathrm{P}$ serial NMRS (Fig. 2) illustrates that DEX preserves NTP, PCr, and $\mathrm{P}_{\mathrm{i}}$, even after $175 \mathrm{~min}$ of HI, compared with saline-pretreated controls. The temporal evolution of NTP, PCr, and $\mathrm{PCr} / \mathrm{P}_{\mathrm{i}}$ are illustrated in Figures 3, 4, and 5, respectively.

NTP levels fall to $32 \%$ of baseline values for saline-treated animals and only to $66 \%$ of baseline for animals pretreated with DEX after $3 \mathrm{~h}$ of HI. After $2.5 \mathrm{~h}$ of recovery, NTP recovers to $75 \%$ of baseline in both treatment groups. The same trend was recognized in PCr levels. In saline-treated animals, the $\mathrm{PCr}$ fell to $46 \%$ of baseline at $3 \mathrm{~h}$ of hypoxia whereas the animals treated with DEX only fell to $67 \%$ of prehypoxic concentrations. As expected, $\mathrm{PCr}$ levels decline earlier and at a faster rate than NTP. Figure 5 indicates that the $\mathrm{P}_{\mathrm{i}} / \mathrm{PCR}$ ratio increases rapidly in saline-treated controls, indicating the rapid increase of $\mathrm{P}_{i}$ and decrease of $\mathrm{PCr}$ during the $\mathrm{HI}$ episode and plateau at nearly 5 times the normal level. In DEX-pretreated animals, the $\mathrm{P}_{\mathrm{i}} / \mathrm{PCr}$ ratio increases to only 1.5 times normal reflecting the undepleted $\mathrm{PCr}$ and only a slight increase in $\mathrm{P}_{\mathrm{i}}$.

Integration of these metabolite levels, over the last $2 \mathrm{~h}(1-3$ h) of $\mathrm{HI}$, for $\mathrm{P}_{\mathrm{i}} / \mathrm{PCr}$ (whose inverse estimates the phosphorylation potential of the tissue $(7,9,10))$ gives a baseline normalized value of $6.92 \pm 1.76$ for the saline and $2.27 \pm 0.26$ for the DEX group $(p<0.001)$ (Fig. 6). There is a strong correlation between the $\mathrm{P}_{\mathrm{i}} / \mathrm{PCr}$ ratio and the neuropathologic score, which agrees with previous reports $(7,9,10)$. Animals with larger integrated $\mathrm{P}_{\mathrm{i}} / \mathrm{PCr}$ values tend to have severe dam-

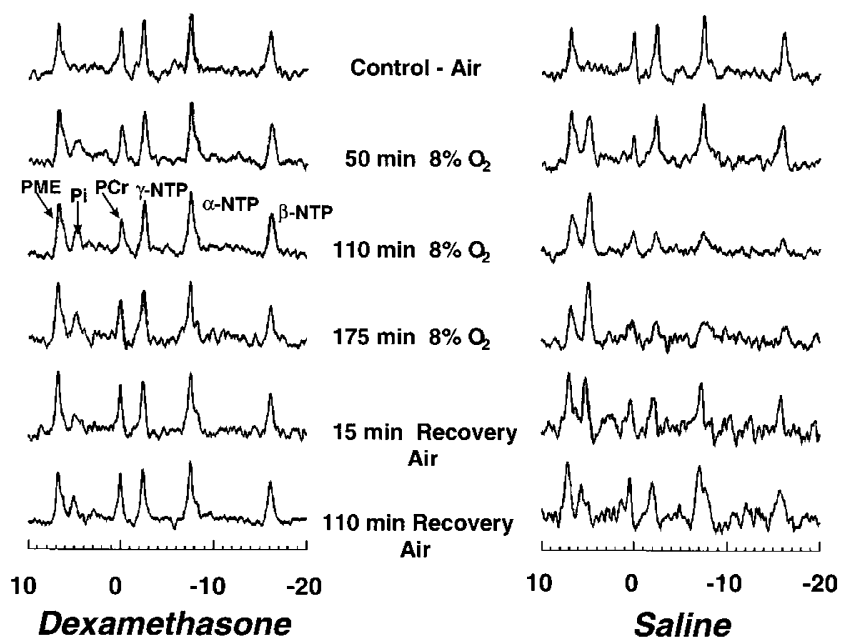

Figure 2. Serial ${ }^{31} \mathrm{P}$ NMR spectra showing the effect of DEX pretreatment on exposure to $3 \mathrm{~h} \mathrm{HI}$ in the 7-d-old rat. The spectra, referenced to $\mathrm{PCr}=0 \mathrm{ppm}$, were acquired at 9.4 Tesla in 10 or 20 min blocks with repetition time (TR) $=$ 2 s. Note the preservation of NTP, PCr, and $\mathrm{P}_{\mathrm{i}}$ at $175 \mathrm{~min}$ of HI with DEX.

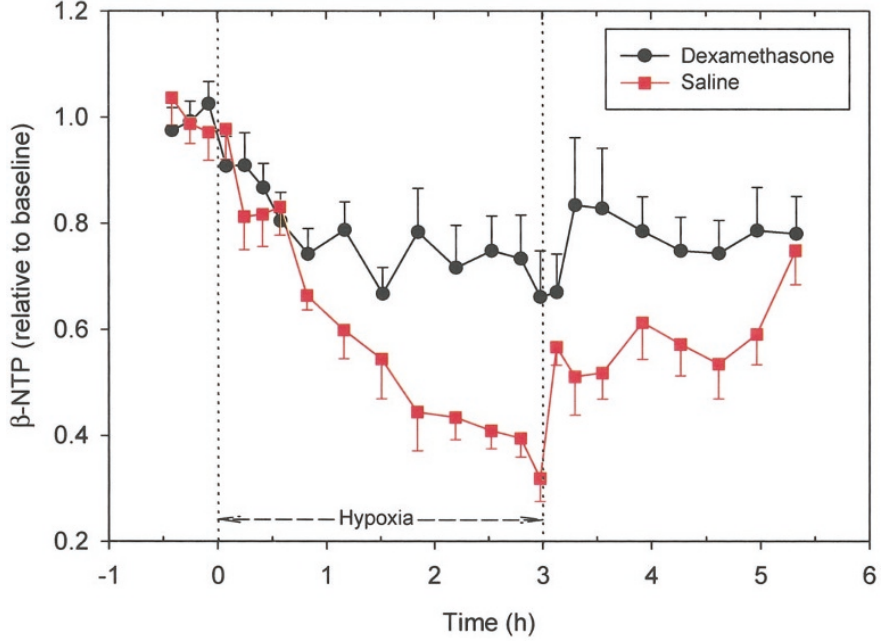

Figure 3. Time course of $[\beta-\mathrm{NTP}]$ in DEX- and saline-treated rat pups exposed to $3 \mathrm{~h}$ of $\mathrm{HI}$ with simultaneous ${ }^{31} \mathrm{P}$ NMRS. The $\beta$-NTP concentration is expressed as a fraction of baseline. Each point represents the average $\beta$-NTP, normalized to the baseline, in the specified group at a given time in the experimental protocol. The $0.5 \mathrm{~h}$ of baseline, $3.0 \mathrm{~h}$ of $\mathrm{HI}$, and $2.5 \mathrm{~h}$ of recovery are divided by vertical dotted lines. The error bars represent the SEM. The significance of the difference between the average $[\beta$-NTP] of the two groups between $1-3 \mathrm{~h}$ of hypoxia was statistically different as determined by the pooled $t$ test $(p<0.001)$.

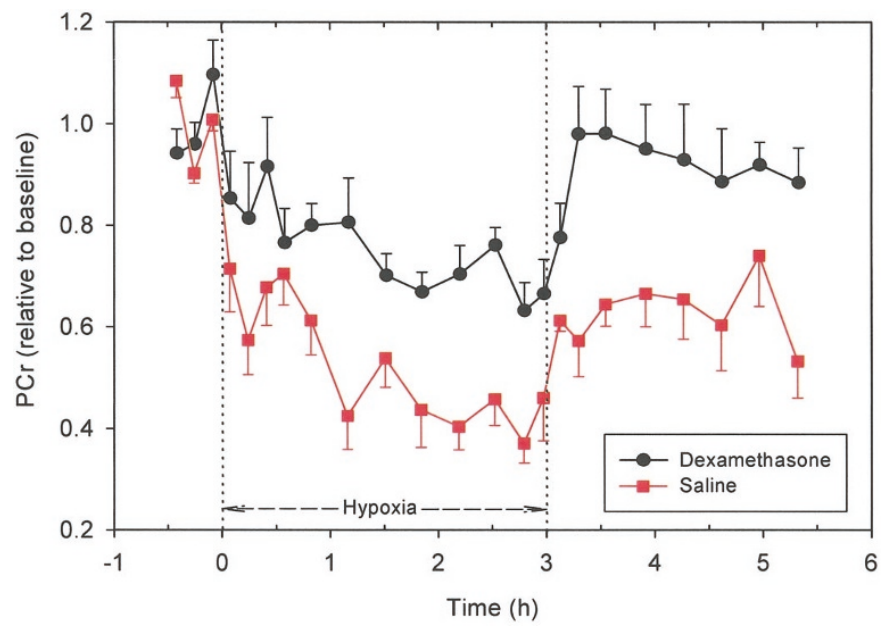

Figure 4. Time course of $[\mathrm{PCr}]$ in DEX- and saline-treated rat pups exposed to $3 \mathrm{~h}$ of $\mathrm{HI}$ with simultaneous ${ }^{31} \mathrm{P}$ NMRS. The $\mathrm{PCr}$ concentration is expressed as a fraction of baseline. Each point represents the average $\mathrm{PCr}$, normalized to the baseline, in the specified group at a given time in the experimental protocol. The $0.5 \mathrm{~h}$ of baseline, $3.0 \mathrm{~h}$ of $\mathrm{HI}$, and $2.5 \mathrm{~h}$ of recovery are divided by vertical dotted lines. The error bars represent the SEM. The significance of the difference between the average [PCr] of the two groups between $1-3 \mathrm{~h}$ of hypoxia was statistically different as determined by the pooled $t$ test $(p<$ $0.001)$.

age at $24 \mathrm{~h}$ post $\mathrm{HI}$, whereas animals pretreated with DEX show no neuronal loss with $\mathrm{P}_{\mathrm{i}} / \mathrm{PCr}$ ratios under 3 .

\section{Brain Edema}

DEX reduced tissue edema to $0.15 \pm 0.78 \%(n=67)$ from $5.03 \pm 1.43 \%(n=40)$ for saline-treated controls $(p<0.0001)$ in bench-top experiments.

Neuropathology. Extensive neuropathologic scoring of the $72 \mathrm{~h}$ experimental group indicated saline-treated controls $(n=$ 


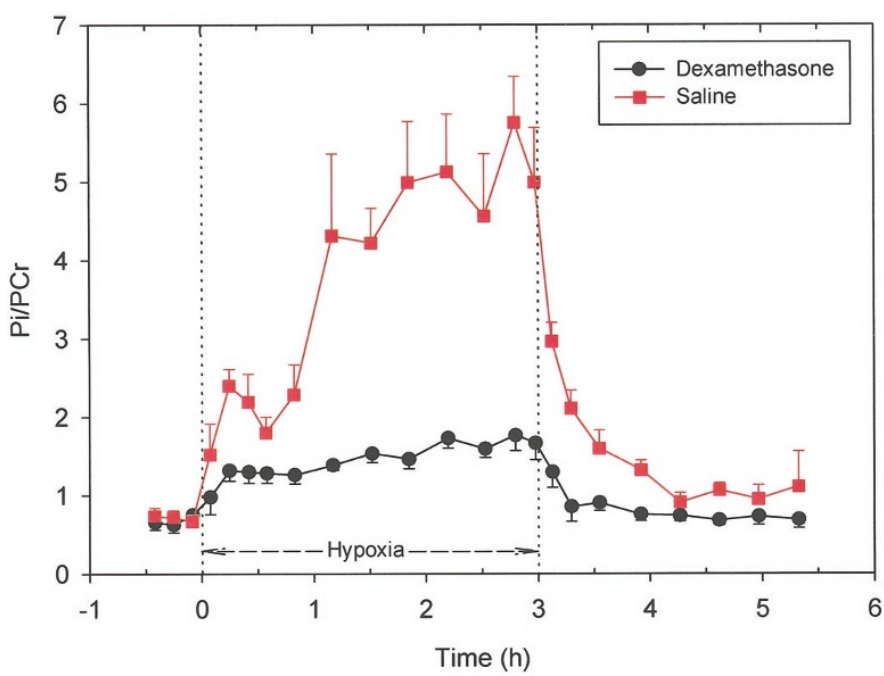

Figure 5. Time course of $\mathrm{P}_{\mathrm{i}} / \mathrm{PCr}$ in DEX- and saline-treated rat pups exposed to $3 \mathrm{~h}$ of $\mathrm{HI}$ with simultaneous ${ }^{31} \mathrm{P}$ NMRS. The $\mathrm{P}_{\mathrm{i}} / \mathrm{PCr}$ concentration is expressed as a fraction of baseline. Each point represents the average $\mathrm{P}_{\mathrm{i}} / \mathrm{PCr}$, normalized to the baseline, in the specified group at a given time in the experimental protocol. The $0.5 \mathrm{~h}$ of baseline, $3.0 \mathrm{~h}$ of $\mathrm{HI}$, and $2.5 \mathrm{~h}$ of recovery are divided by vertical dotted lines. The error bars represent the SEM. The significance of the difference between the average $\mathrm{P}_{\mathrm{i}} / \mathrm{PCr}$ of the two groups between $1-3 \mathrm{~h}$ of hypoxia was statistically different as determined by the pooled $t$ test $(p<0.001)$.

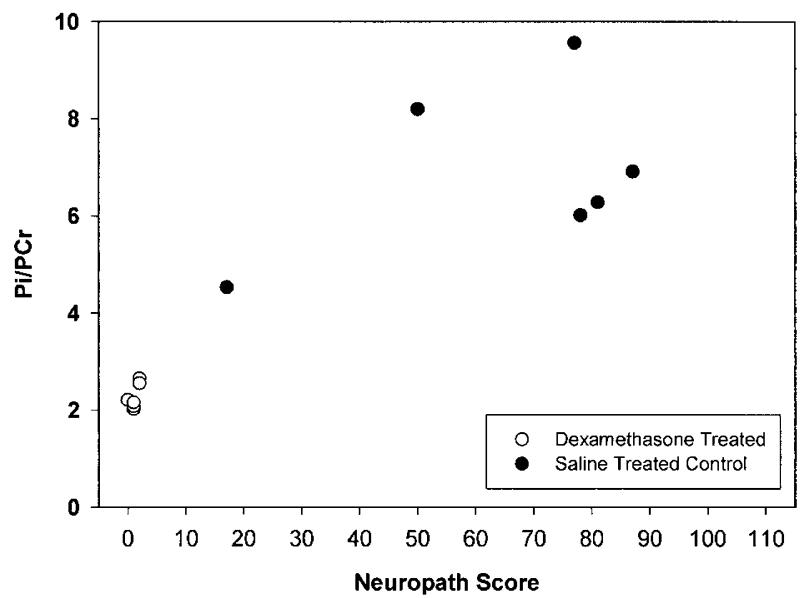

Figure 6. Correlation of normalized $\mathrm{P}_{\mathrm{i}} / \mathrm{PCr}$, calculated from spectra at $1-3 \mathrm{~h}$ of HI, with histologic score from the right hemisphere, measured at $24 \mathrm{~h}$ recovery ( $r=0.84, p<0.001$; Spearman rank). Each symbol represents an individual rat pup that was injected with either saline or DEX, $22 \mathrm{~h}$ before HI. All 6 DEX animals had scores of $0-1$ out of 110 maximum with $\mathrm{P}_{\mathrm{i}} / \mathrm{PCr}$ values below the previously determined threshold of damage.

$10)$ to be significantly damaged $(66 \pm 39)$ when compared with DEX pretreated animals (Fig. 7) $(n=10,0.1 \pm 0.03, p<$ 0.0001 , values are average total score $\pm \mathrm{SD}$, total score has a range of $0-110$ ). Only one animal in the DEX-treated group had any damage. The total score for this animal was 1.0 and only a few neurons were damaged in the $\mathrm{CA}_{1}$ region of the hippocampus.

Saline-treated animals had a majority of neurons damaged in the anterior and posterior cortex with an average damage score of 3.1 (out of 5) over the 12 different regions, $A-F$, and $A^{\prime}-F^{\prime}$ in 10 different animals, and a moderate number of neurons damaged in the hippocampus (average score of 3.5 over 4

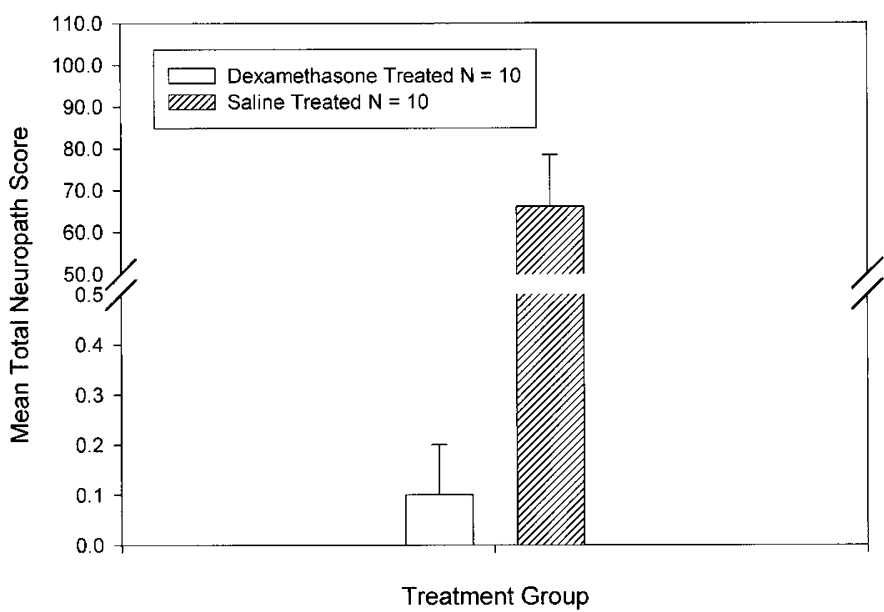

Figure 7. Mean total neuropathologic score at $72 \mathrm{~h}$ of recovery for rat pups treated with DEX $22 \mathrm{~h}$ before $3 \mathrm{~h}$ of $\mathrm{HI}$ and for saline-treated controls. Error bars are one SD. Microscopic evaluations of acute lesions were made from two hematoxylin- and eosin-stained coronal sections, one at the level of the anterior commissure (anterior level) and the other at the level of the infundibulum through the mid-portion of the median eminence (posterior level), which together include structures of the anterior cerebral cortex, striatum, posterior cerebral cortex, dorsal hippocampus, thalamus, and amygdaloid nucleus. A score of $0-5$ was assigned to 22 different regions in these two sections. Scoring is as follows: 0 -normal, $1-\mathrm{few}$ neurons damaged $(1 \%-5 \%), 2$-several neurons damaged $(6 \%-25 \%), 3$-moderate number of neurons damaged $(25 \%-50 \%), 4$ - greater than one-half of neurons damaged $(51 \%-75 \%)$, 5 - majority of all neurons damaged including infarction $(>75 \%)$. Each animal can receive a total neuropathologic score ranging from 0 to 110 (8).

regions), thalamus ( 2.65 over 2 regions), caudate ( 2.75 over 2 regions), and amygdaloid nucleus (2.65 over 2 regions).

Average total neuropathologic scores at $24 \mathrm{~h}$ of recovery for those animals undergoing ${ }^{31} \mathrm{P}$ NMRS indicated that DEX also provided neuroprotection $(1.2 \pm 0.8$ for DEX and $65 \pm 27$ for saline, $p<0.0001)$. The regional average damage score for saline-treated controls in the cortex was a moderate value of 2.8 , severe (4.1) in the hippocampus, moderate in the thalamus (2.8) and caudate nucleus (3.4), and minor in the amygdaloid nucleus (1.3). One animal in the DEX group scored a 1.0 in the lateral caudate nucleus and another animal scored a 1.0 in the $\mathrm{MCA}_{3} / \mathrm{CA}_{4}$ region of the hippocampus.

In summary, in animals pretreated with DEX, only 3 of 16 demonstrated that a few neurons were damaged in the hippocampus and caudate nuclei. When compared with the saline controls, DEX-pretreated animals can be considered "undamaged" after $3 \mathrm{~h}$ of HI. Saline-treated controls show significant evidence of damage - damage to greater than $75 \%$ of neurons in most areas and infarcts in the cortical regions.

Glucose and BHB plasma levels. Table 3 indicates that BHB (the predominant ketone body) was elevated before HI with DEX pretreatment, $0.83 \pm 0.43 \mathrm{mM}$ compared with a level of $0.47 \pm 0.16 \mathrm{mM}$ for saline controls. BHB decreased to $0.43 \pm 0.25 \mathrm{mM}$ following HI with DEX pretreatment and increased to $0.86 \pm 0.39 \mathrm{mM}$ following $\mathrm{HI}$ when animals were pretreated with only saline. Blood glucose levels displayed the opposite trend, increasing from $7.3 \pm 0.84$ to $11.9 \pm 3.39 \mathrm{mM}$ when animals were pretreated with DEX and decreasing from $8.0 \pm 1.1$ to $5.7 \pm 1.4 \mathrm{mM}$ during $\mathrm{HI}$ in saline-pretreated controls. Changes in blood glucose levels during HI with DEX 
Table 3. Blood assay levels

\begin{tabular}{|c|c|c|c|c|}
\hline \multirow{2}{*}{$\begin{array}{c}\text { Concentration } \\
(\mathrm{mmol} / \mathrm{L})\end{array}$} & \multicolumn{2}{|c|}{$0.1 \mathrm{mg} / \mathrm{kg}$ Dexamethasone } & \multicolumn{2}{|c|}{ Saline control } \\
\hline & Pre-HI & Post-HI & Pre-HI & Post-HI \\
\hline Glucose* & $7.3 \pm 0.84, n=10$ & $11.9 \pm 3.39, n=13$ & $8.0 \pm 1.1, n=10$ & $5.7 \pm 1.4, n=9$ \\
\hline
\end{tabular}

Values are represented as mean $\pm \mathrm{SD}$.

* Significance of paired groups at $p<0.05$ except for pre-dexamethasone $v s$ pre-saline.

** All four paired groups are significant.

Table 4. Beta-hydroxybutyrate blood assay levels before HI

\begin{tabular}{ccc}
\hline & $0.1 \mathrm{mg} / \mathrm{kg}$ & \\
& Dexamethasone & Saline control \\
\hline $\begin{array}{c}\text { Concentration } \\
(\mathrm{mmol} / \mathrm{L})\end{array}$ & $0.892 \pm 0.334, n=32$ & $0.658 \pm 0.266, n=43$ \\
\hline
\end{tabular}

Values are represented as mean \pm SD. $p=0.0012$ for difference in means.

and saline pretreatment are the same as described previously $(4,11,12)$. BHB levels before $\mathrm{HI}$, in animals pretreated with DEX, have not been documented before this study.

To further assess blood levels of BHB before HI in PND 6 rat pups, another 75 animals were pretreated with either DEX $(n=32)$ or saline $(n=43)$. Table 4 indicates that there was a statistically significant increase in BHB $(p=0.0012)$ when animals were pretreated with DEX.

\section{Weight Loss}

There was a significant correlation of weight loss between PND 6 (time of injection) and PND 7 (time of HI) with neurologic scoring at either $24 \mathrm{~h}$ (Fig. 8) or $72 \mathrm{~h}$ after HI. If animals lost weight between PND 6 and PND 7, these animals would receive neuroprotection during the $3-\mathrm{h}$ HI episode. Presumably, loss of body mass supports the increased blood ketone bodies.

Figure 9 demonstrates this same body weight variation for the animals that underwent $3 \mathrm{~h}$ of $\mathrm{HI}$ in the bench-top experiments. DEX-pretreated animals lost $3.1 \pm 2.8 \%$ (mean $\pm \mathrm{SD}$ ) of their body weight between PND 6 and PND 7, whereas saline-treated controls gained $9.9 \pm 3.1 \%$ over the same period $(p<0.0001)$. When weight gain was measured between PND 6 and PND 9, there was no statistically significant weight change between the two groups.

Although, the exact pathophysiology that produces tissue damage is complex, cerebral HI severe enough to cause detectable neuropathologic damage in the neonatal animal is consistently associated with major perturbations in cerebral energy metabolism. The altered cellular energy metabolism has numerous effects on cellular processes, which in turn might affect the cell's integrity and viability. The depletion of intracellular NTP concentrations compromises all of the energydependent cellular processes.

Accordingly, during HI there is a shift to increased anaerobic glycolysis. Lactate is the end product of anaerobic glycolysis. Consequently, an increase in the cerebral lactate concentration with an accompanying decrease in $\mathrm{pH}$ has been associated with hypoxic-ischemic insults that produce damage. Lactate levels above 15-20 mmol lactate/kg brain weight have been considered by some investigators as levels that result in

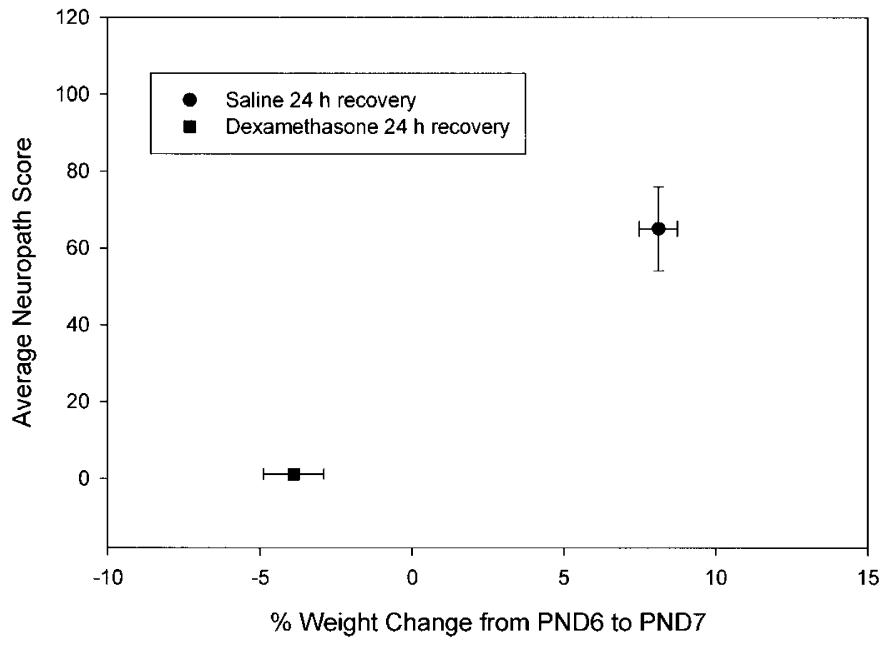

Figure 8. Mean total neuropathologic score at $24 \mathrm{~h}$ of recovery versus mean percent weight change between PND 6 and PND 7 for rat pups treated with DEX $22 \mathrm{~h}$ before $3 \mathrm{~h}$ of hypoxia with simultaneous ${ }^{31} \mathrm{P}$ NMRS and for saline controls. Error bars are $1 \mathrm{SD}$. A good correlation exists between weight loss and neuropathologic score $(p<0.001)$. Animals injected with DEX either loose or gain very little weight before HI.

irreversible damage in vulnerable regions of adult brain tissue (13-15). The accompanying lactacidosis might be the reason why hyperglycemia accentuates brain damage in adult animals $(12,14,25)$. However, high lactate levels do not contribute to damage in neonatal animals $(14,16-18)$.

A compromise in NTP production during HI triggers a cascade of events that, if allowed to continue, ultimately leads to irreversible damage and cell death. In the modified Levine model of perinatal HI, the unilateral common carotid ligation alone does not produce damage (19). It is the combination of partial ischemia with hypoxia that produces damage in this model. By inducing cardiac depression and hypotension, the exposure to reduced oxygen (hypoxia) increases the cerebral ischemia over that produced by the unilateral common carotid artery ligation alone. Consequently, the cerebral blood flow decreases to $15 \%$ to $35 \%$ of normal during HI (20).

The combination of hypoxia with incomplete ischemia produces a limitation in the delivery of both oxygen and metabolic fuels to individual cells as the blood flow to the affected tissue is reduced. Oxidative phosphorylation is dependent upon the delivery of metabolic fuels because the brain stores of glycogen are low (21). As such, studies have focused on the role of substrate limitation in determining subsequent cerebral damage.

Previous studies using the modified Levine model of $\mathrm{HI}$ in neonatal rat pups have demonstrated that during HI the mitochondria paradoxically become oxidized rather than reduced (22). This oxidation of the mitochondria during $\mathrm{HI}$ in the 


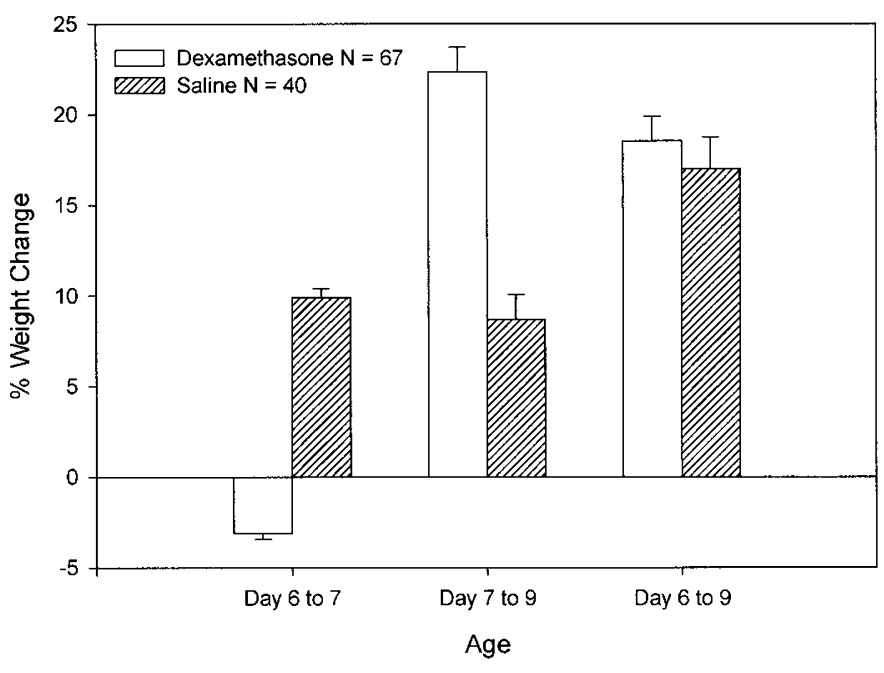

Figure 9. Percent weight change versus age after injection. PND 6 rats were injected with either $0.1 \mathrm{~mL}$ of saline or DEX $22 \mathrm{~h}$ before HI. DEX-treated animals lost $3.1 \pm 2.8 \%$ (mean $\pm \mathrm{SD}$ ) of their body weight at PND 7 whereas saline-treated controls gained $9.9 \pm 3.1 \%(p<0.0001)$. When measured at PND 9, the DEX-treated rats gained $18.5 \pm 11.2 \%$ whereas saline-treated animals gained $17.0 \pm 11.1 \%(p>0.05)$. Error bars are SEM values.

immature rat suggests that the availability of metabolic fuels is limited, resulting in a deficiency of reducing equivalents.

The supposition that substrate limitation contributes to $\mathrm{HI}$ cerebral damage is supported by the finding that hyperglycemia is protective in immature animals. Pretreatment with glucose prolongs survival in immature animals subjected to systemic hypoxia, asphyxia, or cerebral ischemia $(12,14,23)$. In contrast, in adult animals exposed to cerebral ischemia, hyperglycemia accentuates the resulting brain damage. Accentuation of damage in adult animals is thought to be a consequence of the accompanying lactacidosis $(12,14,17,24)$.

Hypoglycemia has the opposite effect on neuropathologic outcome in neonatal animals than adult animals exposed to hypoxia and/or ischemia. Hypoglycemia reduces brain damage in adult animals $(14,25)$, most likely as a consequence of decreased lactate production. Neonatal rats with insulin-induced hypoglycemia develop the same amount of damage as their control littermates when both groups are subjected to HI (25).

Fundamental differences in substrate utilization exist between newborn and adult animals. Under normal conditions, the rate of glucose uptake per gram of brain tissue in the neonate is one-fifth of the rate of glucose uptake in the adult rat (26). In addition, the rate of glucose utilization per gram of brain tissue in the neonate is one-tenth that of the adult rat. The diminished uptake and utilization of glucose in the neonate relative to that of the adult rat may explain in part why hyperglycemia does not result in increased damage in the neonate subjected to HI. The low ratio under normal conditions of glucose utilization to respiration in neonatal brain tissue suggests that alternative fuels are readily used by the neonate (26).

Several factors attest to the utilization of ketone bodies as a primary metabolic fuel in immature brain tissue under normal conditions. Ketone bodies are readily available due to the high fat content of rat milk (27). During the neonatal period, the activity of the enzymes involved in ketone metabolism increase, whereas after weaning, the activity of these enzymes decreases and the activity of the enzymes involved in glycolysis increases (27). The arteriovenous difference of ketone bodies across the brain in neonatal rats correlates with the arterial blood concentration of ketone bodies. In addition, the arteriovenous difference of ketone bodies across the brain is 3-4 times higher in neonatal than in adult rats (28). Since ketone bodies are a major fuel source in the neonate, conditions that lead to ketonemia may be neuroprotective if the damage from $\mathrm{HI}$ is indeed a consequence of substrate limitation.

Fasting that results in ketonemia and mild hypoglycemia has been shown to be mildly protective in the neonate subjected to HI $(25,29)$. Fasting is also neuroprotective in both juvenile and adult animals (30-32). Yager et al. report that the extent of damage is less in fasted neonatal rat pups exposed to HI than in both normoglycemic or insulin-induced hypoglycemic animals. The neuropathologic damage was greater in the insulintreated animals than in the normoglycemic animals, but the difference was not significant. Although the exact actions of insulin in neonatal brain tissue are not known, the difference between the damage in the animals with insulin-induced hypoglycemia, normoglycemia, and fasting may be a consequence of substrate supply (25). Insulin is an anabolic hormone that inhibits ketone body formation in addition to decreasing the levels of circulating glucose, whereas fasting induces the endogenous production of ketone bodies. Although the glucose concentration is lowest in the fasted animals, Yager et al. report a twofold increase in circulating BHB levels in the fasted animals compared with the normoglycemic and insulininduced hypoglycemic animals (25).

Because the increase in mitochondrial $[\mathrm{NAD}+] /[\mathrm{NADH}]$ during HI suggests a lack of reducing equivalents, increasing the availability of a readily metabolized substrate such as BHB produced during fasting may improve the cerebral energy status. Indeed, any mechanism that increases plasma levels of BHB may improve cerebral energy status and prove to be neuroprotective during neonatal HI. Fasting results in a correlation between the circulating blood level of BHB before the hypoxic-ischemic insult and the severity of the resulting damage $(25,29)$. The administration of exogenous BHB has been shown to increase the survival time of immature mice exposed to hypoxic or anoxic conditions (33). In a study in adult animals, the administration of BHB alone was not significantly beneficial but the combination of BHB and glucagon increased hypoxic tolerance (34). In adult animals exposed to ischemia, the administration of 1,3-butanediol induces ketosis and results in reduction of metabolic alterations associated with $\mathrm{HI}$, a reduction in cerebral water content, and improvement in neurologic function, and an increase in blood BHB levels (34-37).

\section{CONCLUSIONS}

${ }^{31} \mathrm{P}$ NMRS demonstrates that cerebral energy metabolism is preserved in DEX-pretreated neonatal rats. As in past studies, there is no HI brain damage with our model if high-energy metabolites are preserved. Tuor et al. (4) have shown that DEX does not alter cerebral blood flow and that glucose injections 
during HI do not account for the neuroprotection. We hypothesize that DEX causes weight loss from catabolism of muscle tissue, which increases pre-HI BHB levels. This result is comparable with $24 \mathrm{~h}$ of fasting, where BHB was increased, high-energy metabolism was preserved, and neuroprotection was provided. Our results suggest that pretreatment with DEX preserves cerebral energy metabolism through ketogenesis, providing alternative NTP-producing substrates.

These experiments indicate that ${ }^{31} \mathrm{P}$ NMRS can be conveniently used to monitor high-energy phosphates during $\mathrm{HI}$ in unanesthetized neonatal rats. The integrated levels of metabolites are a good predictor of which animals will ultimately proceed to infarction or exhibit neuropathologic damage. Ketone bodies are elevated by DEX treatment, which is also a characteristic seen in fasted animals. Both fasted and DEXtreated animals display significantly improved neuroprotection to HI. Precursors to BHB (1,3-butanediol or short-chain fatty acids) might prove more effective in elevating blood ketone levels than by direct injection alone. There is a strong positive correlation between preservation of high-energy metabolites during HI and elevated prehypoxic-ischemic ketone bodies with final neurologic outcome.

\section{REFERENCES}

1. Effect of corticosteroids for fetal maturation on perinatal outcomes. $1995 \mathrm{NIH}$ Consensus Development Panel on the Effect of Corticosteroids for Fetal Maturation on Perinatal Outcomes [see comments]. JAMA 273:413-418

2. Altman DI, Young RS, Yagel SK 1984 Effects of dexamethasone in hypoxic-ischemic brain injury in the neonatal rat. Biol Neonate 46:149-156

3. Barks JD, Post M, Tuor UI 1991 Dexamethasone prevents hypoxic-ischemic brain damage in the neonatal rat. Pediatr Res 29:558-563

4. Tuor UI, Simone CS, Arellano R, Tanswell K, Post M 1993 Glucocorticoid prevention of neonatal hypoxic-ischemic damage: role of hyperglycemia and antioxidant enzymes. Brain Res 604:165-172

5. Tuor UI, Simone CS, Barks JD, Post M 1993 Dexamethasone prevents cerebral infarction without affecting cerebral blood flow in neonatal rats. Stroke $24: 452-457$

6. Tuor UI 1995 Dexamethasone and the prevention of neonatal hypoxic-ischemic brain damage. Ann N Y Acad Sci 765:179-95; discussion 196-197

7. Williams GD, Palmer C, Roberts RL, Heitjan DF, Smith MB 1992 31P NMR spectroscopy of perinatal hypoxic-ischemic brain damage: a model to evaluate neuroprotective drugs in immature rats. NMR Biomed 5:145-153

8. Cataltepe OVR, Heitjan DF, Towfighi J 1995 Effect of status epilepticus on hypoxicischemic brain damage in the immature rat. Pediatr Res 38:251-257

9. Williams GD PC, Heitjan DF, Smith MB 1992 Allopurinol preserves cerebral energy metabolism during perinatal hypoxia-ischemia: a 31P NMR study in unanesthetized immature rats. Neurosci Lett 144:103-106

10. Williams GD, Dardzinski BJ, Buckalew AR, Smith MB 1997 Modest hypothermia preserves cerebral energy metabolism during hypoxia-ischemia and correlates with brain damage: a 31P nuclear magnetic resonance study in unanesthetized neonatal rats. Pediatr Res 42:700-708
11. Vannucci RC, Yager JY 1992 Glucose, lactic acid, and perinatal hypoxic-ischemic brain damage. Pediatr Neurol 8:3-12

12. Vannucci RC 1992 Cerebral carbohydrate and energy metabolism in perinatal hypoxic- ischemic brain damage. Brain Pathol 2:229-234

13. Hall R, Murdoch J 1990 Brain protection: physiological and pharmacological considerations. Part II: the pharmacology of brain protection. Can J Anaesth 37:762-777

14. Vannucci RC 1990 Experimental biology of cerebral hypoxia-ischemia: relation to perinatal brain damage. Pediatr Res 27:317-326

15. Rehncrona SRI, Siesjo BK 1981 Brain lactic acidosis and ischemic cell damage: 1 . biochemistry and neurophysiology. J Cereb Blood Flow Metab 1:297-311

16. Palmer C, Brucklacher RM, Christensen MA, Vannucci RC 1990 Carbohydrate and energy metabolism during the evolution of hypoxic-ischemic brain damage in the immature rat. J Cereb Blood Flow Metab 10:227-235

17. Vannucci RC, Vasta F, Vannucci SJ 1987 Cerebral metabolic responses of hyperglycemic immature rats to hypoxia-ischemia. Pediatr Res 21:524-529

18. Welsh FA, Vannucci RC, Brierley JB 1982 Columnar alterations of NADH fluorescence during hypoxia-ischemia in immature rat brain. J Cereb Blood Flow Metab 2:221-228

19. Rice JEd, Vannucci RC, Brierley JB 1981 The influence of immaturity on hypoxicischemic brain damage in the rat. Ann Neurol 9:131-141

20. Vannucci RC, Lyons DT, Vasta F 1988 Regional cerebral blood flow during hypoxia-ischemia in immature rats. Stroke 19:245-250

21. Murdoch J, Hall R 1990 Brain protection: physiological and pharmacological considerations. Part I: the physiology of brain injury. Can J Anaesth 37:663-671

22. Yager JY, Brucklacher RM, Vannucci RC 1991 Cerebral oxidative metabolism and redox state during hypoxia-ischemia and early recovery in immature rats. Am J Physiol 261:H1102-1108

23. Voorhies TM, Rawlinson D, Vannucci RC 1986 Glucose and perinatal hypoxicischemic brain damage in the rat. Neurology 36:1115-1118

24. Yager JY, Brucklacher RM, Vannucci RC 1992 Cerebral energy metabolism during hypoxia-ischemia and early recovery in immature rats. Am J Physiol 262:H672-677

25. Yager JY, Heitjan DF, Towfighi J, Vannucci RC 1992 Effect of insulin-induced and fasting hypoglycemia on perinatal hypoxic-ischemic brain damage. Pediatr Res $31: 138-142$

26. Moore TJ LA, Regen DM, Tarpley HL, Raines PL 1971 Brain glucose metabolism in the newborn rat. Am J Physiol 221:1746-1753

27. Krebs HA WD, Bates MW, Page MA, Hawkins RA 1971 The role of ketone bodies in caloric homeostasis. Adv Enzyme Regul 9:387-409

28. Hawkins RA WD, Krebs HA 1971 Ketone-body utilization by adult and suckling rat brain in vivo. Biochem $\mathrm{J}$ 122:13-18

29. Collins B 1995 The Effect of Ketonemia on Cerebral Energy Metabolism and Cerebral Damage in Immature Rats Exposed to Hypoxia-Ischemia: An In Vivo 31P NMRS Study. [thesis] Pennsylvania State University, Hershey, PA

30. Go KG, Prenen G, Korf J 1988 Protective effect of fasting upon cerebral hypoxicischemic injury. Metab Brain Dis 3:257-263

31. Marie CBA, Gueldry S, Bralet J 1990 Fasting prior to transient cerebral ischemia reduces delayed neuronal necrosis. Metab Brain Dis 5:65-75

32. Myers RE Yamaguchi S 1977 Nervous system effects of cardiac arrest in monkeys. Preservation of vision. Arch Neurol 34:65-74

33. Holowach-Thurston JHR 1989 Ketonemia increases survival of young mice in anoxic as well as hypoxic environments. Pediatr Res 25:326A

34. Eiger SM KJ, D'Alecy LG 1980 Hypoxic tolerance enhanced by B-hydroxybutyrateglucagon in the mouse. Stroke 11:513-517

35. Gueldry S, Marie C, Rochette L, Bralet J 1990 Beneficial effect of 1,3-butanediol on cerebral energy metabolism and edema following brain embolization in rats. Stroke $21: 1458-1463$

36. Gueldry S, Bralet J 1994 Effect of 1,3-butanediol on cerebral energy metabolism. Comparison with beta-hydroxybutyrate. Metab Brain Dis 9:171-181

37. Lundy EF DJ, Luyck B, Zelenock GB, D’Alecy LG 1985 Reduction of neurologic deficit by 1,3-butanediol induced ketosis in Levine rats. Stroke 16:855-860 